\title{
Ação do ácido ascórbico exógeno na qualidade fisiológica de sementes de feijão de corda envelhecidas artificialmente
}

\section{Action of exogenous ascorbic acid on physiological quality of cowpea seeds artificially aged}

\author{
Jean Carlos de Araújo Brilhante ${ }^{1}$; Alexandre Bosco de Oliveira ${ }^{1 *}$; \\ José Wendney Lima e Silva²; Joaquim Enéas Filho ${ }^{3}$
}

\begin{abstract}
Resumo
O objetivo desse estudo foi avaliar os efeitos do pré e pós-tratamento com ácido ascórbico na redução dos danos ocasionados pelo envelhecimento em sementes de feijão de corda, as quais foram envelhecidas em câmara de envelhecimento artificial $\left(45^{\circ} \mathrm{C}, 99 \%\right.$ U.R., no escuro) por $72 \mathrm{~h}$, sendo submetidas a quatro tratamentos: T1 - sementes não envelhecidas e não tratadas com ácido ascórbico (AsA); T2 - sementes envelhecidas e não tratadas com AsA; T3 - sementes que antes do envelhecimento foram submetidas a um tratamento com AsA a $0,85 \mathrm{mM}$; T4 - sementes que após o envelhecimento foram submetidas a um tratamento com AsA a $0,85 \mathrm{mM}$. O envelhecimento das sementes por $72 \mathrm{~h}$ (T2) provocou danos significativos nas membranas celulares das sementes de feijão de corda, como foi evidenciado pelo aumento no vazamento de eletrólitos, maior nível de peroxidação de lipídios e menor porcentagem de germinação quando comparado com o controle (T1). O T4 conseguiu igualar aos resultados apresentados pelo controle, apresentando um menor vazamento de eletrólitos e peroxidação de lipídios, bem como maior germinação, quando comparado com o T2. A aplicação exógena de ácido ascórbico a $0,85 \mathrm{mM}$ nas sementes de feijão de corda após o envelhecimento artificial pode atenuar efeitos deletérios na integridade de membranas e favorecer a qualidade fisiológica das sementes.

Palavras-chave: Vigna unguiculata, membranas, acido ascórbico, envelhecimento artificial
\end{abstract}

\begin{abstract}
The aim of this study was to evaluate the effects of pre-treatment and post-treatment with ascorbic acid in reducing the damage caused by aging in cowpea seeds, which were aged in artificial accelerated aging chamber $\left(45^{\circ} \mathrm{C}, 99 \%\right.$ relative humidity in the dark) for $72 \mathrm{~h}$ and it were subjected to four treatments: T1 - non-aged seeds were not treated with ascorbic acid (AsA); T2 - non-aged seeds treated with AsA; T3 - seeds before aging were subjected to a treatment with AsA to $0.85 \mathrm{mM}$; T4 - seeds after aging were subjected to a treatment with a $0.85 \mathrm{mM}$ AsA. The aging of seeds for $72 \mathrm{~h}$ (T2) caused significant damage in the cell membranes of cowpea seeds, as evidenced by a increase in electrolyte leakage, higher level of lipid peroxidation and a lower germination percentage, when compared with the control (T1). T4 results were like the control treatment, with a lower electrolyte leakage and lipid peroxidation, well as a higher germination percentage, when compared with T2. The exogenous application of $0.85 \mathrm{mM}$ ascorbic acid in cowpea seeds after artificial aging can mitigate its detrimental effects on the membranes integrity and seed physiological quality.
\end{abstract}

Key words: Vigna unguiculata, membranes, ascorbic acid, artificial aging

\footnotetext{
${ }^{1}$ Eng $^{\text {os }}$ Agr $^{\text {os }}$, D.Sc., Dept ${ }^{\text {de }}$ Fitotecnia, Unviersidade Federal do Ceará, CCA/UFC, Av. Mister Hull, S/N, Campus do Pici, CEP 60356-001, Fortaleza, CE. E-mail: brilhanteufc@yahoo.com.br; alexandrebosco@ufc.br

2 Discente de Graduação em Agronomia, Dept ${ }^{\circ}$ de Fitotecnia, CCA/UFC, Fortaleza, CE. E-mail: wendney ce@hotmail.com

${ }^{3}$ Biólogo, Prof. D.Sc., Dept ${ }^{\circ}$ de Bioquímica e Biologia Molecular, CCA/UFC, Fortaleza, CE. E-mail: joaquime@ufc.br

* Autor para correspondência
} 


\section{Introdução}

A cultura do feijão de corda é importante no nordeste brasileiro, principalmente no aspecto social, como geradora de empregos e garantia de reserva de subsistência. As sementes de feijão de corda, principalmente em pequenas propriedades, são armazenadas de forma inadequada, em condições não controladas, contribuindo assim, para a perda da qualidade fisiológica (VIEIRA; YOKOYAMA, 2000).

Os problemas de armazenamento de produtos agrícolas constituem objeto de estudo permanente, visando prolongar ao máximo a qualidade e assim evitar perdas desnecessárias nos grãos armazenados (VIEIRA; YOKOYAMA, 2000). A qualidade fisiológica de sementes tem sido um dos aspectos mais pesquisados nos últimos anos, em decorrência das sementes estarem sujeitas a uma série de mudanças degenerativas de origem bioquímica, fisiológica e física após a sua maturação, sendo todas associadas com a redução do vigor (CARVALHO; NAKAGAWA, 2000). Alternativas têm sido pesquisadas visando um melhor desempenho de lotes de sementes com qualidade fisiológica inferior, enquanto ainda não se tem um método adequado para a preservação das sementes durante o armazenamento convencional.

Os testes de vigor são capazes de avaliar o grau de deterioração das sementes, constituindo uma ferramenta importante na avaliação da qualidade fisiológica de diferentes lotes de sementes comerciais (DUTRA; MEDEIROS FILHO; TEÓFILO, 2006). Existem também, testes dirigidos à avaliação do comportamento das sementes, quando submetidas a condições específicas de ambiente, geralmente estressantes, como o teste de envelhecimento acelerado. Na literatura, constata-se que os eventos rápidos mais estudados estão relacionados com os processos iniciais da sequência de deterioração como a degradação das membranas celulares e a redução das atividades respiratória e biossintética (BINOTTI et al., 2008).
As sementes de plantas superiores representam excelentes modelos para o estudo do envelhecimento, pois a perda da viabilidade pode ser facilmente induzida experimentalmente por meiode testes de vigor (KRANNER et al., 2006). O teste do envelhecimento acelerado em sementes de feijão de corda [Vigna unguiculata (L.) Walp.] constitui um eficiente teste de vigor para avaliar diferentes lotes de sementes e predizer sua qualidade fisiológica durante a exposição ao período prolongado de armazenamento (SALINAS et al., 2001).

Trabalhos com uma grande variedade de culturas têm sido desenvolvidos no sentido de prolongar a armazenabilidade de sementes pela aplicação de antioxidantes às sementes (CHHETRI; RAI; BHATTACHARJEE, 1993; DE TULIO; ARRIGONI, 2003). Além disso, técnicas de envigoramento de sementes e algumas técnicas de osmocondicionamento pré-semeadura vêm sendo utilizadas, visando a uniformização do estande e maior rapidez na emergência de plântulas no campo (CHHETRI; RAI; BHATTACHARJEE, 1993; OLIVEIRA; GOMES FILHO, 2010).

O pré-tratamento das sementes com antioxidantes não enzimáticos aumenta o vigor, e com isso, o potencial de armazenamento dessas sementes às condições adversas de temperatura e umidade (MAITY et al., 2000). É sugerido que o tratamento prévio das sementes com antioxidantes como o ácido ascórbico aumenta o vigor e prolonga a armazenabilidade das sementes devido, principalmente, à remoção de espécies reativas de oxigênio (ERO) (SMIRNOFF, 2000). Entretanto, são escassos na literatura estudos sobre o efeito da aplicação de antioxidantes não enzimáticos na melhoria da viabilidade e do potencial de armazenamento de sementes de feijão de corda.

O presente estudo teve como objetivo avaliar o efeito do pré e do pós-tratamento comácido ascórbico na proteção e redução dos danos ocasionados pelo envelhecimento na integridade das membranas de sementes de feijão de corda. 


\section{Material e Métodos}

O material vegetal utilizado foi sementes de feijão de corda [Vigna unguiculata (L.) Walp.], cultivar EPACE 10, disponibilizadas pelo Banco de GermoplasmadoLaboratório de Análise de Sementes (LAS) do Departamento de Fitotecnia do Centro de Ciências Agrárias (CCA) da Universidade Federal do Ceará (UFC). As sementes de feijão de corda, cv. EPACE 10, obtidas do banco de germoplasma, foram selecionadas segundo critérios de tamanho, aparência e sanidade, a fim de homogeneizar as condições experimentais e posteriormente desinfetadas. Estas foram distribuídas e incubadas em caixas "gerbox" devidamente colocadas em câmara de envelhecimento artificial acelerado $\left(45^{\circ} \mathrm{C}, 99 \%\right.$ U.R., no escuro) para promover o envelhecimento das mesmas por $72 \mathrm{~h}$ (DELOUCHE; BASKIN, 1973). As sementes foram submetidas a quatro tratamentos: $\mathrm{T} 1$ - sementes não envelhecidas e não tratadas com ácido ascórbico (AsA), isto é, o tratamento controle (SNE); T2 - sementes envelhecidas e não tratadas com AsA (SE); T3 - sementes que antes do envelhecimento foram submetidas a tratamento com $0,85 \mathrm{mM}$ de AsA (SEPré-T); T4 - sementes que após o envelhecimento foram submetidas a tratamento com $0,85 \mathrm{mM}$ de AsA (SE-Pós-T).

Os respectivos tratamentos com o AsA, T3 e $\mathrm{T} 4$, foram realizados, através da pré-semeadura das sementes de feijão-de-corda, em papel germitest, embebido com solução contendo ácido L-ascórbico (PA, Sigma-Aldrich $\left.{ }^{\circledR}\right)$ a $0,85 \mathrm{mM}\left(150 \mathrm{mg} \mathrm{L}^{-1}\right)$ num volume de 2,5 o peso do papel (BRASIL, 2009) por um período de 4h. Após cada um dos tratamentos citados foram feitas as seguintes análises:
A) Determinação da massa fresca, massa seca e umidade das sementes: A determinação da massa fresca (MF) foi feita logo após a aplicação dos tratamentos, pela pesagem em balança analítica, em seguida o material foi congelado em freezer à temperatura de $-80{ }^{\circ} \mathrm{C}$ para posterior liofilização. A massa seca (MS) foi obtida após a liofilização das amostras e a umidade (U) das sementes foi determinada utilizando-se a seguinte relação: $\mathrm{U}=(\mathrm{MF}-\mathrm{MS}) /(\mathrm{MF}) \times 100$. Os dados de MF e MS foram expressos em gramas e a umidade das sementes foi dada em porcentagem.

B) Teste da condutividade elétrica (CE) e a porcentagem de danos de membranas (DM): Foram conduzidos conforme a metodologia citada por Vieira e Krzyzanowski (1999), utilizandose quatro repetições de 25 sementes de cada tratamento, onde foram pesadas em balança analítica e depois colocadas em copos plásticos contendo 75 $\mathrm{mL}$ de água destilada. Os copos foram colocados em germinador a $25^{\circ} \mathrm{C}$ por $24 \mathrm{~h}$ (Figura 14A) e logo depois se procedeu a leitura das soluções contendo os lixiviados das sementes em aparelho condutivímetro DIGIMED CD 21 previamente calibrado. Os resultados das leituras foram divididos pela massa das amostras e a condutividade foi expressa em $\mu \mathrm{S} \mathrm{cm}^{-1} \mathrm{~g}^{-1}$ de semente. Após leitura a 25 ${ }^{\circ} \mathrm{C}$ as amostras foram colocadas em Erlenmeyer em banho maria com água fervente por $1 \mathrm{~h}$ e realizouse novas leituras no condutivímetro. A porcentagem de danos de membranas (\%DM) das sementes foi estimada pelo método de vazamento de eletrólitos descrito por Blum e Ebercon (1981) pela seguinte relação: $\% \mathrm{DM}=\left(\mathrm{L}_{1} / \mathrm{L}_{2}\right) \times 100$, onde $\mathrm{L}_{1}$ representa a leitura de condutividade do extrato a $25^{\circ} \mathrm{C}$ após $24 \mathrm{~h}$ de incubação e $\mathrm{L}_{2}$ a leitura após a fervura em banho maria por $1 \mathrm{~h}$. 
Figura 1. Massa fresca (A), massa seca (B) e umidade (C) das sementes de feijão de corda, cultivar EPACE 10, submetidas a diferentes tratamentos $(\mathrm{SNE}=$ Sementes não envelhecidas; $\mathrm{SE}=$ Sementes envelhecidas por $72 \mathrm{~h}$; SE-Pré-T $=$ sementes pré-tratadas com $0,85 \mathrm{mM}$ de AsA e após envelhecidas por $72 \mathrm{~h}$ e SE-Pós-T $=$ sementes envelhecidas por $72 \mathrm{~h}$ e pós-tratadas com $0,85 \mathrm{mM}$ de AsA). Colunas seguidas pela mesma letra minúscula, nos diferentes tratamentos não são significativamente diferentes $(\mathrm{p} \leq 0,05)$ pelo teste de Tukey.

A
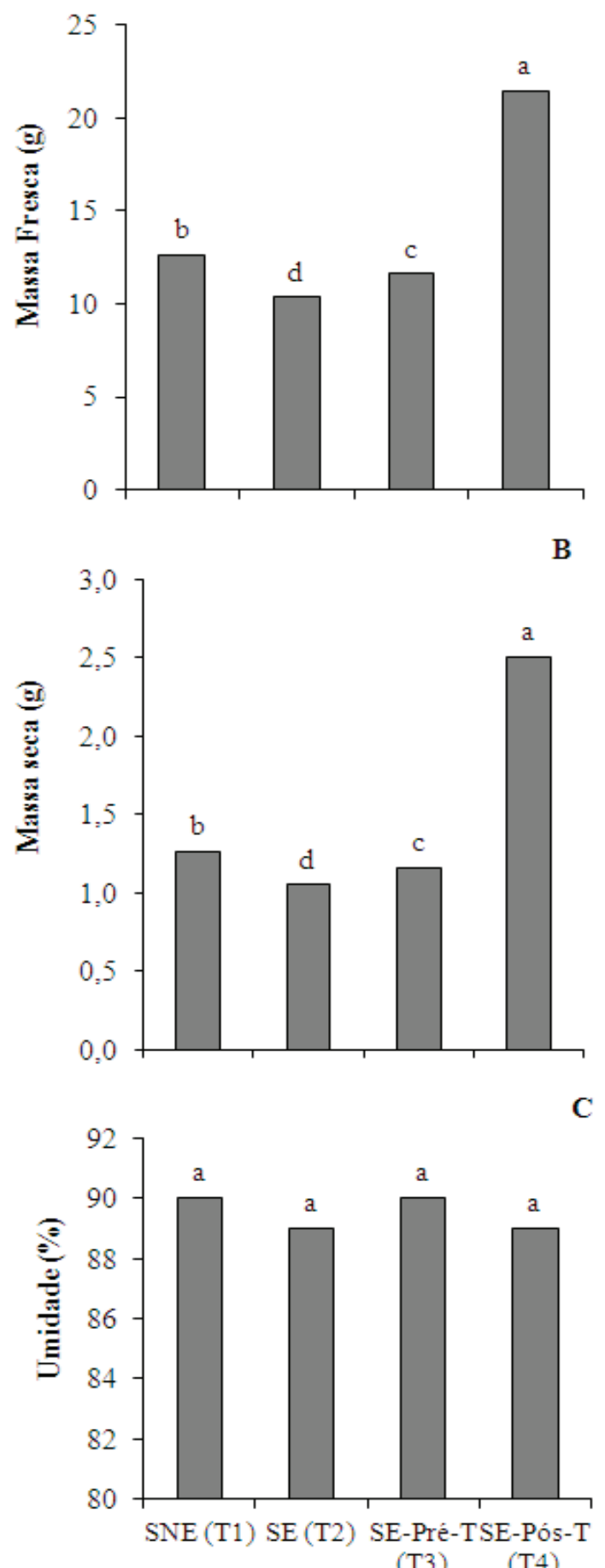

Tratamentos

Fonte: Elaboração dos autores. 
C) Peroxidação de lipídios: A peroxidação de lipídios foi mensurada pelo método de Heath e Packer (1968). Para tanto, amostras de $50 \mathrm{mg}$ de tecido liofilizado foram maceradas com $1,5 \mathrm{~mL}$ de ácido tricloroacético (TCA) $1 \%(\mathrm{~m} / \mathrm{v})$. A suspensão foi centrifugada a $10.000 \mathrm{~g}$ por 15 minutos e o sobrenadante utilizado para os ensaios. A mistura contendo $500 \mu \mathrm{L}$ do extrato mais $2 \mathrm{~mL}$ do reagente contendo ácido tiobarbitúrico (TBA) a $0,5 \%(\mathrm{~m} / \mathrm{v})$, dissolvido em TCA a $20 \%(\mathrm{~m} / \mathrm{v})$ foi incubada em banho maria com água fervente por 1 hora. As leituras foram realizadas nas absorbâncias de 532 e $660 \mathrm{~nm}$. A segunda leitura foi subtraída da primeira para obtenção da leitura específica e a peroxidação de lipídios foi calculada através do coeficiente de extinção molar de $155 \mathrm{mM}^{-1} \mathrm{~cm}^{-1}$ e expressa em nmol MDA-TBA g ${ }^{-1}$ MS.

D) Teste de germinação: Foram utilizadas quatro repetições de 50 sementes de cada tratamento, semeadas em rolos de papel germitest, umedecidos com água o equivalente a 2,5 vezes a massa do papel do substrato seco e então colocado para germinar a $25{ }^{\circ} \mathrm{C}$ em BOD. As avaliações foram realizadas no $3^{\circ}$ e $7^{\circ}$ dias após a semeadura e os resultados expressos em porcentagem de germinação com base no número de plântulas normais, segundo orientações das Regras para Análises de Sementes (RAS) para esta espécie (BRASIL, 2009).

Utilizou-se o delineamento experimental inteiramente casualizado com quatro tratamentos, constando de quatro repetições cada. Os dados foram submetidos à análise de variância pelo teste $\mathrm{F}$ e as médias foram comparadas pelo teste de Tukey ao nível de $5 \%$ de probabilidade.

\section{Resultados e Discussão}

Os dados apresentados na Figura 1A revelam que o envelhecimento artificial por $72 \mathrm{~h}$ (T2) provocou redução significativa na massa fresca das sementes, aproximadamente $18 \%$ quando se compara com o controle (T1). No entanto, quando se fez um prétratamento das sementes de feijão de corda com 0,85
$\mathrm{mM}$ de AsA, antes do envelhecimento, a redução foi somente de $8 \%$, como observado no tratamento T3. Já a massa fresca das sementes que foram tratadas com 0,85 mM de AsA após o envelhecimento (T4) foi quase duas vezes superior àquela do tratamento controle (T1). Resultados semelhantes também foram observados para a massa seca das sementes, onde no T4 houve um aumento de aproximadamente duas vezes em relação ao controle (T1), enquanto o T2 proporcionou redução de cerca de 16\% na massa seca das sementes (Figura 1B).

$\mathrm{O}$ envelhecimento acelerado tem se mostrado eficiente para avaliar o vigor de lotes de sementes de feijoeiro e acompanhar a sua variação durante o período de armazenamento, principalmente porque acelera o processo de deterioração das sementes (DELOUCHE; BASKIN, 1973; MARCOS FILHO, 2005). Já é conhecido na literatura que a umidade relativa alta combinada a uma temperatura elevada existente na câmara de envelhecimento artificial, acelera o processo de deterioração das sementes, reduzindo assim sua massa total (ABBA; LOVATO, 1999), como observado neste estudo.

Não houve modificações significativas na umidade das sementes nos tratamentos T1, T2 e T4 (Figura 1C). Entretanto foi observado que o tratamento $\mathrm{T} 3$ provocou acentuado aumento no teor de água das sementes, o que pode ser explicado pela natureza higroscópica das sementes que, dependendo das condições ambientais nas quais são submetidas, podem ganhar ou perder água facilmente (COPELAND; MCDONALD, 1995). As condições de umidade elevada e altas temperaturas existentes na câmara de envelhecimento durante o envelhecimento artificial das sementes, aliado como o pré-tratamento com AsA do T3, talvez tenham interferido significativamente no aumento do teor de água das sementes do T3, pois esse tratamento ocasionou uma pré-embebição das sementes e isso provavelmente tenha acentuado o efeito negativo do envelhecimento. Além disso, foi observado visualmente que houve relevante crescimento de fungos no T3 com o envelhecimento (dados não 
apresentados). Os resultados obtidos neste estudo, confirmam a afirmação de Vieira e Yokoyama (2000), os quais relatam que o armazenamento de sementes de feijoeiro com teor de água superior a $13 \%$ resultará em danos provocados por mudanças no metabolismo celular, como o aumento da atividade enzimática e respiratória das sementes, propiciando o desenvolvimento de fungos, que serão favorecidos pela alta temperatura.

$O$ teste da condutividade elétrica (CE) tem se mostrado eficiente na distinção entre lotes de sementes de feijão de corda das cultivares Setentão e EPACE 10 (DUTRA; MEDEIROS FILHO; TEÓFILO, 2006). Neste trabalho, conforme se verifica na Figura 2A, o teste da C.E também se mostrou eficiente na identificação dos danos provocados pelo envelhecimento nas sementes de feijão de corda, cultivar EPACE 10, como também já relatado em sementes de soja por Salinas et al. (2001). O envelhecimento artificial provocou um maior vazamento de eletrólitos nas sementes do T2 (51,81 $\mu \mathrm{S} \mathrm{cm}^{-1} \mathrm{~g}^{-1}$ de semente), comparado com o controle (T1), o qual apresentou valores de 39,96 $\mu \mathrm{S} \mathrm{cm} \mathrm{cm}^{-1} \mathrm{~g}^{-1}$ de semente. Já o T4 conseguiu igualarse aos resultados apresentados pelo controle, não havendo assim diferença significativa entre esses tratamentos, apresentando um menor vazamento de eletrólitos quando comparado com o T2. Entretanto, o T3 apresentou um vazamento de eletrólitos de $81,81 \mu \mathrm{S} \mathrm{cm}^{-1} \mathrm{~g}^{-1}$ de semente, ou seja, com valores superiores até mesmo em relação ao T2 $(51,81 \mu \mathrm{S}$ $\mathrm{cm}^{-1} \mathrm{~g}^{-1}$ de semente). Os resultados obtidos para CE corroboraram com os dados observados para o percentual de danos de membranas, que avalia a integridade das membranas celulares, onde os T2 e T3 apresentaram os maiores percentuais de danos nas membranas quando comparado com os demais tratamentos (Figura 2B). Nesse sentido, Vieira e Krzyzanowski (1999) reportam que em função da desorganização das membranas celulares, as sementes tendem a reduzir assim o seu vigor, o que pode ser verificado pelo aumento do vazamento de solutos durante o processo de embebição das sementes.

$\mathrm{O}$ tratamento T4 funcionou como um revigoramento das sementes de feijão-de-corda, pois foi capaz de reduzir os danos provocados pelo envelhecimento, como mostra os resultados referentes à integridade de membranas, quando comparado com o tratamento controle T1 (Figura 2B). Isso justifica, a importância da aplicação desse tratamento T4, principalmente pelas péssimas condições de armazenamento com que as sementes de feijão-de-corda estão sujeitas principalmente nas regiões semiáridas, além do baixo vigor com que essas sementes chegam às mãos dos produtores. Nesse sentido seria muito importante então, à aplicação desse tratamento de revigoramento das sementes, a fim de que possa melhorar a qualidade fisiológica dessas e com isso o seu potencial produtivo.

Quando se avaliou a integridade das membranas celulares, através do nível de peroxidação de lipídios, os resultados mostram que o envelhecimento artificial provocou aumento de 51\% no nível de peroxidação de lipídios do $\mathrm{T} 2$, em relação ao controle (T1). Esse aumento foi ainda maior no T3, o qual foi $80 \%$ superior ao tratamento controle (Figura 2C). Em estudos com sementes de Ginko biloba L. foi mostrado um significativo aumento da peroxidação de lipídios tanto no embrião quanto no endosperma durante o aumento do período de armazenamento das sementes (TOMMASI et al., 2006). Outros estudos demonstram que um dos eventos iniciais da seqüência de deterioração das sementes durante o processo de envelhecimento é a degradação das membranas celulares (BINOTTI et al., 2008), principalmente devido a peroxidação de lipídios induzida pelo envelhecimento, que potencialmente danifica as membranas de tecidos de sementes (SUNG; JENG, 1994). De modo semelhante ao que foi verificado no presente estudo, Oliveira et al. (2011), trabalhando com plântulas de sorgo, também constataram aumento dos teores malonialdeído, o produto final da peroxidação de lipídios, em função do envelhecimento acelerado das sementes. 
Figura 2. Vazamentos de eletrólitos (A), porcentagem de danos de membranas (B) e peroxidação de lipídios (C) das sementes de feijão de corda, cultivar EPACE 10, submetidas a diferentes tratamentos (SNE = Sementes não envelhecidas; $\mathrm{SE}=$ Sementes envelhecidas por $72 \mathrm{~h}$; SE-Pré-T $=$ sementes pré-tratadas com $0,85 \mathrm{mM}$ de AsA e após envelhecidas por $72 \mathrm{~h}$ e SE-Pós-T = sementes envelhecidas por $72 \mathrm{~h}$ e pós-tratadas com $0,85 \mathrm{mM}$ de AsA). Colunas seguidas pela mesma letra minúscula, nos diferentes tratamentos não são significativamente diferentes $(\mathrm{p} \leq 0,05)$ pelo teste de Tukey.
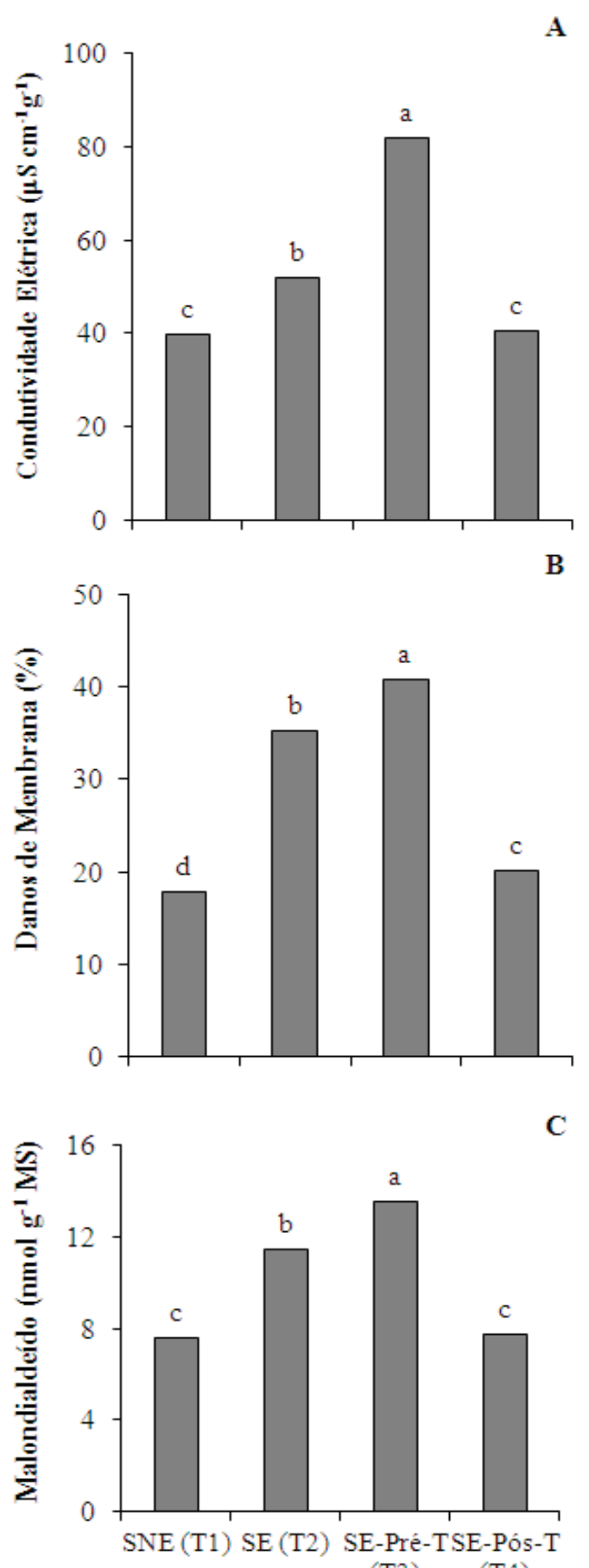

(T3)

(T4)

Tratamentos

Fonte: Elaboração dos autores. 
O envelhecimento artificial (T2) provocou danos significativos nas membranas celulares das sementes de feijão de corda, confirmadopor um aumento significativo no vazamento de eletrólitos no teste da condutividade elétrica e no percentual de danos de membranas, além de maior nível de peroxidação de lipídios (Figura 2). Entretanto, o T4 proporcionou uma redução na peroxidação de lipídios, atingindo valores próximos aos do controle (Figura 2C), resultados estes semelhantes ao observado com folhas de plantas de milho sob estresse hídrico pulverizadas com ácido ascórbico (DOLATABADIAN; MODARRES SANVY; SHARIFI, 2009). Contudo, cabe aqui ressaltar que embora na literatura existam resultados sobre o efeito inibitório do AsA sobre a peroxidação de lipídios, o mecanismo real desse efeito ainda não está esclarecido (DOLATABADIAN; MODARRES SANAVY, 2008).

Estudos recentes têm mostrado que a presença de antioxidantes, como o ácido ascórbico, protege a semente contra a peroxidação de lipídios e as espécies reativas de oxigênio (ERO), induzidas pelo envelhecimento das sementes (FOYER; NOCTOR, 2005). Quando as sementes de algodão foram envelhecidas artificialmente a $40^{\circ} \mathrm{C}$ e $100 \%$ de umidade relativa tiveram suas membranas deterioradas, sendo isso correlacionado com a acumulação de peróxidos e redução na germinação (ANURADHA; KUMAR, 2003). O mesmo foi observado no experimento aqui apresentado, com as sementes do T2, onde houve um aumento significativo da peroxidação de lipídios em função do envelhecimento artificial por $72 \mathrm{~h}$ (Figura 2C).

No teste de germinação foi observado que o envelhecimento (T2) provocou significativa redução na porcentagem de germinação das sementes de feijão de corda, de aproximadamente $19 \%$, quando se comparou com a germinação das sementes do T1 (Figura 3). Essa redução foi mais drástica ainda no $\mathrm{T} 3$, equivalente a $35 \%$, enquanto no $\mathrm{T} 4$, as sementes apresentaram uma porcentagem de germinação até mesmo superior à observada no tratamento controle. Esse comportamento está de acordo com o verificado por Dolatabadian e Modarres Sanavy (2008), onde o tratamento de sementes de oleaginosas com ácido ascórbico melhorou o potencial de germinação dessas sementes quando submetidas ao armazenamento prolongado. Desse modo, um importante papel do AsA no controle da divisão celular já foi proposto na literatura (POTTERS et al., 2002), embora o mecanismo molecular subjacente a este fenômeno ainda não esteja tão claro. 
Figura 3. Porcentagem de germinação das sementes de feijão de corda, cultivar EPACE 10, submetidas a diferentes tratamentos $(\mathrm{SNE}=$ Sementes não envelhecidas; $\mathrm{SE}=$ Sementes envelhecidas por $72 \mathrm{~h}$; SE-Pré-T = sementes prétratadas com $0,85 \mathrm{mM}$ de AsA e após envelhecidas por $72 \mathrm{~h}$ e SE-Pós-T = sementes envelhecidas por $72 \mathrm{~h}$ e póstratadas com $0,85 \mathrm{mM}$ de AsA). Colunas seguidas pela mesma letra minúscula, nos diferentes tratamentos não são significativamente diferentes $(\mathrm{p} \leq 0,05)$ pelo teste de Tukey.

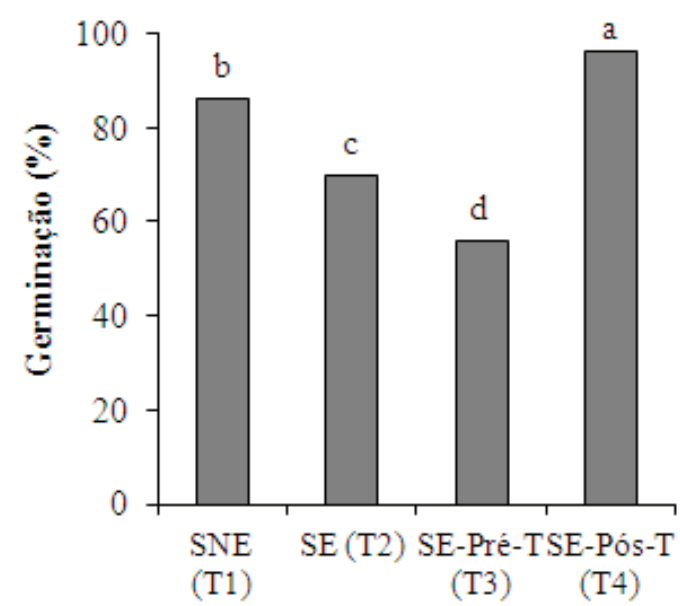

Tratamentos

Fonte: Elaboração dos autores.

\section{Conclusão}

A aplicação exógena de ácido ascórbico a 0,85 $\mathrm{mM}$ nas sementes de feijão de corda, cultivar EPACE 10, após o envelhecimento artificial, atenua os efeitos deletérios na integridade das membranas, provocados pelo envelhecimento artificial, e favorece a qualidade fisiológica das sementes.

\section{Agradecimentos}

Ao Instituto Nacional de Ciência e Tecnologia em Salinidade (INCTSal/CNPq) e ao Conselho Nacional para o Desenvolvimento Científico e Tecnológico (CNPq) pelo apoio financeiro para a realização desta pesquisa.

\section{Referências}

ABBA, E. J.; LOVATO, A. Effect of seed storage temperature and relative humidity on maize (Zea mays L.) seed viability and vigour. Seed Science and Technology, Zürich, v. 27, n. 1, p. 101-114, 1999.

ANURADHA, G.; KUMAR, A. Changes in oxidative stress enzymes during artificial ageing in cotton (Gossypium hirsutum L.) seeds. Journal Plant Physiology, Minneapolis, v. 160, n. 9, p. 1093-1100, 2003.

BINOTTI, F. F. S.; KUNIKO, I. H.; CARDOSO, E. D.; ALVES, C. Z.; SÁ, M. E.; ARF, O. Efeito do período de envelhecimento acelerado no teste de condutividade elétrica e na qualidade fisiológica de sementes de feijão. Acta Scientiarum. Agronomy, Maringá, v. 30, n. 2, p. 247-254, 2008.

BLUM, A.; EBERCON, A. Cell membrane stability as a measure of drought and heat tolerance in wheat. Crop Science, Madison, v. 21, n. 1, p. 43-47, 1981.

BRASIL. Ministério da Agricultura, Pecuária e Abastecimento. Regras para análise de sementes / Ministério da Agricultura, Pecuária e Abastecimento. Secretaria de Defesa Agropecuária. Brasília, DF: MAPA/ ACS, 2009. 399 p. 
CARVAlHO, N. M.; NAKAGAWA, J. Sementes: ciência, tecnologia e produção. 4. ed. Jaboticabal, SP: FUNEP/UNESP, 2000. 424 p.

CHHETRI, D. R.; RAI, A. S.; BHATTACHARJEE, A. Chemical manipulation of seed longevity of four crop species in an unfavourable storage environment. Seed Science and Technology, Zürich, v. 14, n. 2, p. 269-300, 1993.

COPELAND, L. O.; MCDONALD, M. B. Seed science and technology. New York: Chapman \& Hall, 1995. 410 p.

DE TULIO, M. C.; ARRIGONI, O. The ascorbic acid system in seeds: to protect and to serve. Seed Science Research, California, v. 13, n. 4, p. 249-260, 2003.

DELOUCHE, J. C.; BASKIN, C. C. Accelerated aging techniques for predicting the relative storability of seed lots. Seed Science and Technology, Zürich, v. 1, n. 2, p. 427-452, 1973.

DOLATABADIAN, A.; MODARRES SANAVY, S. A. M. Effect of the ascorbic acid, pyridoxine and hydrogen peroxide treatments on germination, catalase activity, protein and malondialdehyde content of three oil seeds. Notulae Botanicae Horti Agrobotanici Cluj-Napoca, Cluj-Napoca, v. 36, n. 2, p. 61-66, 2008.

DOLATABADIAN, A.; MODARRES SANVY, S. A. M.; SHARIFI, M. Alleviation of water deficit stress effects by foliar application of ascorbic acid on Zea mays L. Journal of Agronomy and Crop Science, Malden, v. 195 , n. 5, p. 347-355, 2009.

DUTRA, A. S.; MEDEIROS FILHO; TEÓFILO, E. M. Condutividade elétrica em sementes de feijão caupi. Revista Ciência Agronômica, Fortaleza, v. 37, n. 2, p. 166-170, 2006.

FOYER, C. H.; NOCTOR, G. Redox homeostasis and antioxidant signaling: a metabolic interface between stress perception and physiological responses. The Plant Cell, Norwich, v. 17, n. 7, p. 1866-875, 2005.

HEATH, R. L.; PACKER, L. Photoperoxidation in isolated chloroplasts. I. Kinetics and stoichiometry of fatty acid peroxidation. Archives in Biochemistry and Biophysics, New York, v. 125, n. 3, p. 189-198, 1968.

KRANNER, I.; BIRTIC, S.; ANDERSON, K. M.; PRITCHARD, H. W. Glutathione half-cell reduction potential: a universal stress marker and modulator of programmed cell death? Free Radical Biology and Medicine, Indianapolis, v. 40, n. 12, p. 2155-2165, 2006.
MAITY, S.; BANERJEE, G.; ROY, M.; PAL, C.; PAL, B.; CHAKRABARTI, D.; BHATTACHARJEE, A. Chemical induced prologation of seed viability and stress tolerance capacity of mung bean seedlings. Seed Science and Technology, Zürich, v. 28, n. 1, p. 155-162, 2000.

MARCOS FILHO, J. Fisiologia de sementes de plantas cultivadas. Piracicaba, SP: FEALQ, 2005. 495 p.

OLIVEIRA, A. B.; GOMES FILHO, E. Efeito do condicionamento osmótico na germinação e vigor de sementes de sorgo com diferentes qualidades fisiológicas. Revista Brasileira de Sementes, Brasília, v. 32, n. 3, p. 25-34, 2010.

OLIVEIRA, A. B.; GOMES-FILHO, E.; ENÉASFILHO, J.; PRISCO, J. T.; ALENCAR, N. L. M. Seed priming effects on growth, lipid peroxidation, and activity of ROS scavenging enzymes in NaCl-stressed sorghum seedlings from aged seeds. Journal of Plant Interactions, Turim, v. 11, n. 4, p. 1-9, 2011.

POTTERS, G.; DE GARA, L.; ASARD, H.; HOREMANS, N. Ascorbate and glutathione guardians of the cell cycle, partners in crime? Plant Physiology and Biochemistry, Bari, v. 40, n. 6-8, p. 537-548, 2002.

SALINAS, A. R.; YOLDJIAN, A. M.; ROQUE; CRAVIOTO, M. Y.; BISARO, V. Pruebas de vigor y calidad fisiológica de semillas de soja. Pesquisa Agropecuária Brasileira, Brasília, v. 36, n. 2, p. 371-379, 2001.

SMIRNOFF, N. Ascorbic acid: metabolism and functions of a multi-facetted molecule. Current Opinion in Plant Biology, London, v. 3, n. 3, p. 229-235, 2000.

SUNG, J. M.; JENG, T. L. Lipid peroxidation and peroxide-scavenging enzymes associated with accelerated aging of peanut seed. Physiologia Plantarum, Blacksburg, v. 91, n. 1, p. 51-55, 1994.

TOMMASI, F.; PACIOLLAA, C.; DE PINTO, M. C.; DE GARA, L. Effects of storage temperature on viability, germination and antioxidant metabolism in Ginkgo biloba L. seeds. Plant Physiology and Biochemistry, Bari, v. 44, n. 5-6, p. 359-368, 2006.

VIEIRA, E. H. N.; YOKOYAMA, M. Colheita, processamento e armazenamento. In: VIEIRA, E. H. N.; RAVA, C. A. Sementes de feijão-produção e tecnologia. Santo Antonio de Goiás, GO: Embrapa Arroz e Feijão, 2000. p. 233-248.

VIEIRA, R. D.; KRZYZANOWSKI, F. C. Teste de condutividade elétrica. In: KRZYZANOWSKI, F. C.; VIEIRA, R. D.; França Neto, J. B. (Ed.). Vigor de sementes: conceitos e testes. Londrina: ABRATES, 1999. p. 4.1-4.26. 